\title{
A fresh (water) perspective on the impacts of the NAO on North Atlantic ecology
}

\section{Dietmar Straile}

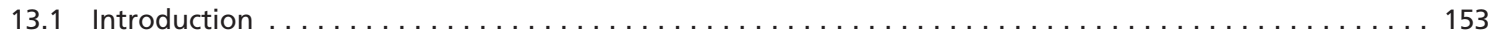

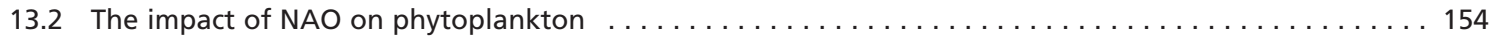

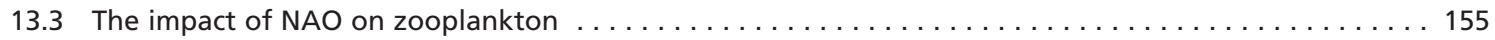

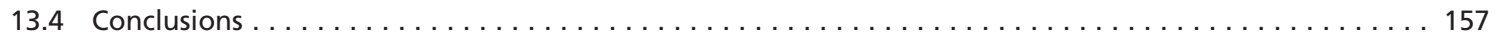

\subsection{Introduction}

North Atlantic climate variability does not only have an influence on North Atlantic ecosystems as described in the previous chapters and by Drinkwater et al. (2003), but influences terrestrial and freshwater ecosystems across the Northern Hemisphere (Ottersen et al. 2001; Mysterud et al. 2003; Stenseth et al. 2002; Straile et al. 2003b). Its impact on freshwater ecosystems has been documented on an area ranging from Lake Mendota in the United States to Lake Baikal in Russia, from Lake Kallavesi in Finland to the Caspian Sea (Straile et al. 2003b). In an increasing number of studies, the North Atlantic Oscillation (NAO) is shown to influence the physics, chemistry, as well as the biology of rivers and lakes, with biological impacts encompassing various trophic levels. A review on NAO impacts was recently provided by Straile et al. (2003b) and will not be repeated here. Instead, this chapter is an essay on selected aspects of NAO impacts on freshwater ecosystems, which might shed some light or pose new questions on the NAO impacts on the North Atlantic.

There is one aspect of lake ecosystems, which makes them easier to study compared to marine ecosystems: their size. Because of their smaller size, the physical environment of most freshwater plankton ecosystems may be considered to some extant as simplified because large current systems do not exist as in the ocean and hence cannot influence the abundance of plankton organisms at distinct sampling sites. Horizontal transport is a major topic in this book's chapters of climate impacts on phytoplankton (Chapter 4), zooplankton (Chapter 5), as well as fish populations (Chapter 6) in the North Atlantic. The impact of horizontal transport on plankton abundance is of such pronounced importance that the term 'translation' has been coined to account for this effect (Chapter 5). Ecological consequences of changes in horizontal transport are manyfold. Direct and indirect effects may be distinguished: the direct effect of changes in horizontal transport is that a distinct species or community will be transported to the site A instead of site B. This, however, might imply important secondary and indirect effects for the transported species/community but also for the local communities at both sites A and B. Site A might be less or more suitable for the growth and reproduction of the transported species than site B because of local differences in temperature and/or food and/or predator abundance (spatial match or mismatch; Cushing 1990). Likewise, local communities at sites A and B will probably experience a different future as the transported species or community is now more or less abundant, which might change food availability and/or predation pressure. Additionally, local and transport responses might act simultaneously. For example, NAO related changes in growth and survival of cod larvae in the Barents Sea are thought to result from changes in temperature and prey availability, the latter resulting from 
increased inflow of Calanus finmarchicus into the Barent Sea and high C. finmarchicus growth and survival in the Barent Sea due to higher local temperature (Ottersen and Stenseth 2001). Given, this complexity, it is not surprising that distinguishing between the relative influence of physical processes such as climate-induced translations versus biological processes is considered to be a fundamental problem in biological oceanography (Chapter 5). Obviously, freshwater ecosystems offer the possibility to study the local impact of climatic variations such as the NAO on, for example, the population dynamics of phytoplankton, zooplankton, and fish species without the confounding effects of horizontal transport. Hence, a look across the salinity border might provide insights into the role and importance of local physical and biological responses of aquatic ecosystems to the NAO and climate variability in aquatic ecosystems.

\subsection{The impact of NAO on phytoplankton}

The relative importance of local processes versus transport processes in determining local plankton abundances will depend on the intrinsic growth rates of species, which in turn will be largely determined by their body size. Due to their small size, phytoplankton will respond fast to local changes in climatic conditions, which then might be as important as transport responses. Clearly, NAO related changes of transport processes are also of importance for phytoplankton. For example, increased oceanic inflow into the North Sea resulted into increased numbers and abundances of oceanic species such as the diatom Thalassiothrix longissima (Edwards et al. 2001). However, high phytoplankton growth rates should allow phytoplankton populations to show a fast numerical response to local conditions. Marine phytoplankton populations have been shown to respond to the NAO in terms of seasonal phenology, growth rates, species composition, and biomass as described by Smayda and coworkers in Chapter 4 . Because of the multitude of possible mechanisms by which the NAO might influence phytoplankton populations it is, however, extremely difficult to understand the reasons for NAO related changes within a specific local phytoplankton assemblage.

In lakes, NAO related changes of light availability seem to be important to understand the impact of the NAO on phytoplankton. Light availability in many temperate lakes during winter/early spring is controlled by ice cover. In some of these lakes, ice-break-up in late winter/early spring is tightly related to the NAO (Livingstone 1999; Weyhenmeyer et al. 1999; Straile et al. 2003b). Warm winters in Central and Northern Europe in the early 1990s resulted into a pronounced reduction of ice cover duration compared with, for example, the 1980s (Adrian et al. 1999; Weyhenmeyer et al. 1999; Weyhenmeyer 2001). As ice cover strongly reduces light availability for phytoplankton, ice-break-up is usually associated with the start of the phytoplankton bloom. Earlier ice-break-up hence was shown to result into a considerable advancement of the timing of the phytoplankton peak in, for example, Lake Erken, Sweden and Müggelsee, Germany. In Lake Erken, the timing of the spring peak advanced by approximately one month during the last decades and the advancement was significantly related to the NAO (Weyhenmeyer et al. 1999). The timing of the phytoplankton maximum in Müggelsee was also related to the NAO and the average date of the phytoplankton peak advanced by approximately one month from the 6th of May during the years 1979-87 to the 7th of April during 1988-98 (Gerten and Adrian 2000). In addition to the influence of the NAO and ice-break off on bloom timing, the timing of ice-break off was also related to phytoplankton species composition. In both Müggelsee and Lake Erken, high NAO years favoured the growth of diatoms relative to other phytoplankton species as diatom blooms developed only under ice-free conditions when turbulent conditions prevented diatoms from sinking off the euphotic zone (Adrian et al. 1999; Weyhenmeyer et al. 1999). In contrast to lakes with winterly ice-cover, no significant relationship between bloom initiation nor phytoplankton peak abundance and the NAO was observed in a deep lake, Lake Constance, Germany, although water temperature in this lake was closely associated with the NAO (Straile 2000). In Lake Constance, a complete ice cover is a rare event (it only occurred once in this century in 1963, being a year with a very low NAO index value) and the start of the phytoplankton bloom is controlled by the absence of water mixis below $20 \mathrm{~m}$ (Gaedke et al. 1998). Mixis events below this critical depth seem to occur in Lake Constance independently from the NAO. In fact, the vertical distribution of nutrients and oxygen during winter and early springs suggests that winter mixis is complete within the upper $100 \mathrm{~m}$ of the water column 
independently from winter conditions, while after warmer winters (high NAO years) mixis below $100 \mathrm{~m}$ was less likely than and after cold winters (Straile et al. 2003a). Phytoplankton blooms in Lake Constance were also observed at cold-water temperature during short periods with absence of mixis (Gaedke et al. 1998), suggesting that direct effects of water temperature on phytoplankton growth rates might be only of secondary importance.

Phytoplankton might be indirectly influenced by climatic variability due to its influence on herbivore grazing rates. For example, Smayda and coworkers suggest in Chapter 4 that increased grazing rates due to higher abundances of cladocerans and Acartia hudsonica in high NAO years resulted into decreased abundance of the diatom Detonula confervacea. NAO associated grazing impacts on phytoplankton seem to be common in Central European Lakes (see below). In many temperate lakes, temperature controlled mass development of herbivores results into a so-called clear-water phase due to the elimination of algae from the water column (Lampert et al. 1986). The timing of the clear-water phase increased during the last three decades on average by approximately two weeks in several European lakes and the interannual variability is tightly associated with the NAO (Straile 2002). Seasonal advancement of the clear-water phase was less than that of ice break-up and in magnitude similar to phenological responses in terrestrial ecosystems (Chmielewski and Rötzer 2002) (Fig. 13.1). The

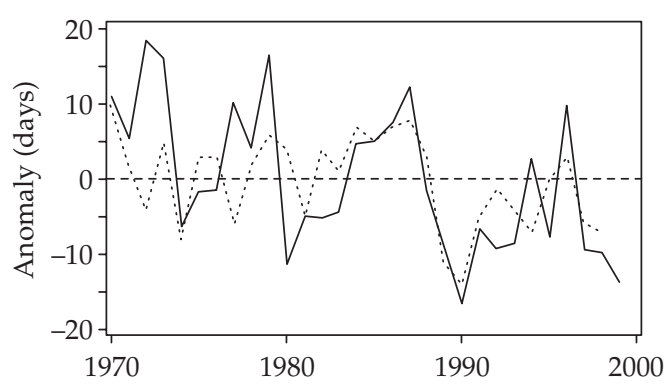

Figure 13.1 Anomalies of average European tree leafing dates (dotted line) from Chmielewski and Rötzer (2002) and average Central European clear water timing (thick line). Clear-water anomalies are adjusted for the effects of altitude, latitude, and lake depth (Straile 2002). Over the whole study period, the average date of leafing was the 23rd of April, and the average clear-water date was on the 9th of June. Both time series are significantly related to the NAO winter index and also significantly related to each other (all $p<0.05$, after linear detrending: all $p<0.05$ ). advancement of the timing of the clear-water phase demonstrates that impacts of the NAO need not be confined to winter, when the NAO has its strongest teleconnections to European climate variability. Clear-water timing, which occurs usually in late spring/early summer, is still rather closely related to the winter state of the NAO. The high heat-carrying capacity of water and the growth and grazing of herbivore populations carry on the meteorological signal towards summer.

\subsection{The impact of NAO on zooplankton}

The chapter of Pershing and coworkers on NAO impact on North Atlantic zooplankton (4) demonstrates how important horizontal transport mechanisms are for the understanding of the abundance of copepod species. Interannual variability of C. finmarchicus in the northwest Atlantic as well as $C$. finmarchicus and Calanus helgolandicus in the northeast Atlantic cannot be understood without considering horizontal transport. This chapter further summarizes work, which shows that a thorough understanding of the seasonal dynamics and the life history of species is necessary to understand the association between climate and species dynamics.

The impact of the NAO on copepod populations in lakes is less evident as compared to marine copepods, but also as compared to other freshwater zooplankton taxa. The winter abundance of Eudiaptomus gracilis in Esthwaite water, United Kingdom, has been shown to be significantly related to the NAO (George and Hewitt 1999). Additionally, Adrian (1997) has shown that winter conditions in Heiligensee in Berlin, Germany, influence population dynamics of copepods species. Given the strong influence of the NAO on winter temperature in this region (Straile and Adrian 2000; Gerten and Adrian 2001) a relationship of copepod population dynamics with the NAO in Heiligensee is likely. Interestingly, in both cases increased food abundance was considered to be the cause for the increased abundance of copepods: In Heiligensee, increased food abundance, that is, phytoflagellates and rotifers, during warm winters probably increased the survival of nauplii and copepodid stages of the cyclopoid copepod Cyclops vicinus (for resulting indirect effects see Adrian 1997). Copepod species in Lake Constance show no strong relationship with the NAO (Straile, unpublished data). In this deep lake, water temperatures but not phytoplankton abundance during winter and early 
spring was closely associated with the NAO (Straile 2000; Straile et al. 2003a). However, in contrast to copepods, spring population dynamics of cladocerans, for example, daphnids, were strongly associated with the NAO in Lake Constance. As food abundance is high and predation pressure is low during the period of Daphnia spring increase, interannual variability in population growth was most probably a direct consequence of water temperature variability (Straile 2000). Abundance of daphnids increased during spring within less than two months approximately 1000-fold. As the speed of population growth during this highly dynamic period seems to be controlled largely by temperature, even small interannual differences in water temperature may have huge effects on abundance. For example, average daphnid biomass during May varied by a factor of 200 between a rather low NAO year (1987) and a high NAO year (1990) in Lake Constance (Straile and Geller 1998). Within a subsequent study, it was shown that Daphnia spring dynamics in the small hypertrophic Müggelsee was also related to the NAO (Straile and Adrian 2000). Despite differing in several limnological characteristics and being $700 \mathrm{~km}$ apart from Lake Constance, interannual variability in Daphnia spring population growth in Müggelsee was closely related to Daphnia interannual variability in Lake Constance. Also in Müggelsee, the response of growth rates to changes in water temperatures was considered to link Daphnia population dynamics to the NAO (Straile and Adrian 2000).

Indirect evidence suggests an influence of the NAO on Daphnia population dynamics during spring in many Central European lakes. The timing of mass occurrences of daphnids can be inferred from its grazing impact on phytoplankton. Massive Daphnia grazing in late spring results in many temperate lakes into the so-called clear-water phase, a short and distinctive period of high water transparency (Lampert et al. 1986). Due to the impact of the NAO on Daphnia population growth, the timing of this 'foot print' of Daphnia grazing is also tightly related to the NAO in both Lake Constance and in Müggelsee (Straile 2000; Straile and Adrian 2000) but also in several other Central European lakes of variable morphology and trophic status (Scheffer et al. 2001; Straile 2002). Hence, the NAO seemed to have a striking synchronizing effect on the population dynamics of cladoceran herbivores including the predator-prey interaction with its food resources in Central European lakes during the last decades.
The analysis of freshwater zooplankton longterm data sets suggests that species with high intrinsic growth rates as parthenogenetically reproducing cladocerans (and rotifers; Gerten and Adrian 2000) seem to be more likely to respond fast to local changes in environmental conditions than species with complex life cycles and a comparatively long developmental time, for example, copepods. Hence, local responses of zooplankton populations in the North Atlantic might be also more important for taxa, which have higher maximum population growth rates as copepods. For example, in coastal regions the microphagous cladoceran Penilia avirostris might be able to respond fast to changed environmental conditions. Likewise, growth rates of tunicates are among the highest reported for metazoans (Madin and Deibel 1998). As a consequence of its high growth rates, tunicates have been shown to build up mass occurrences leading to clear-water phases (Bathmann 1988) comparable to the impacts of mass developments of daphnids. Obviously such mass occurrences will have important consequences for carbon fluxes and export production in the ocean (Bathmann 1988; Andersen 1998). More information on the population dynamics of these species seem to be needed in order to obtain a more complete picture on the impacts of the NAO on the functioning of North Atlantic ecosystems especially regarding the fate of biogenic material (Chapter 3). A second potentially very important missing link in the understanding of NAO effects or more generally climate change effects on carbon flows and export production in oceans, but also in lakes, is the impact of the $\mathrm{NAO} /$ climate change on protozoans. It is now generally agreed that protozoans are important in both lakes and the oceans as grazers of primary production (Müller et al. 1991; Gaedke and Straile 1994; Neuer and Cowles 1994), as remineralizers of nutrients (Caron and Goldman 1990; Ferrier-Pagès and Rassoulzadegan 1994) and in the transfer of carbon and nutrients to higher trophic levels (Carrick et al. 1991; Gaedke et al. 2002). Unfortunately, until now it is not clear whether and to what extent protozoan population dynamics and the protozoan share of total nutrient remineralization and secondary production are influenced by climate variability. Models of the response of carbon fluxes in the North Atlantic to climate variability will definitely have to consider zooplankton species in addition to copepods. 


\subsection{Conclusions}

Overall, the work on NAO impacts in freshwater ecosystems underlines the importance of a thorough understanding of the seasonal dynamics and life history of species for a better understanding and prediction of climate variability on aquatic ecosystems (Chapter 5). Due to differences in seasonal occurrence and in life history characteristics species will respond differently to the NAO and may also be affected by the NAO via different mechanisms. In this respect, it is tempting to note that responses of freshwater copepods to the NAO have been suggested to be due to changes in food concentrations, whereas the responses of freshwater cladocerans seemed to be due to altered water temperatures. Effects of the NAO on a distinct population can be strong and may be passed on to other taxa, for example, due to grazing or predation. Such food web interactions may prolong the influence of the NAO beyond the time period of teleconnections between the North Atlantic and local climate. Furthermore, evidence from European lakes suggests that such indirect effects may be as strong that they can be observed synchronously across a large area. 